\title{
Reflexiones sobre el dolor: un análisis a partir de La forma que se despliega ${ }^{1}$
}

\section{Reflections on Pain: an Analysis from La forma que se despliega}

\author{
Lucía Laura M. Galazzi \\ Universidad de Buenos Aires. \\ Facultad de Filosofía y Letras. Buenos Aires, Argentina \\ laugalazzi@fibertel.com.ar
}

Resumen - Este artículo aborda la puesta en escena de La forma que se despliega (Veronese, 2003) y la conceptualización del dolor humano con medios artísticos o filosóficos. También examina, en su primer apartado, la mayor parte de la pieza teatral que refiere la experiencia del dolor y releva el papel que juegan las construcciones sociales de la naturaleza humana en la comunicación del mismo. La segunda parte aborda el final de la obra, que propone una reflexión meta-discursiva acerca de la posibilidad de escenificar el dolor, trasladando ese problema a la filosofía. Se presentan finalmente diferentes vías de resolución, para concluir proponiendo una conceptualización en los límites de lo pensable, que aspira a la construcción de interpretaciones que transforman y dan sentido a la experiencia.

Palabras clave: experiencia estética, dolor, naturaleza humana, biodrama.

Abstract - This article approaches the staging of La forma que se despliega (Veronese, 2003) and the conceptualization of human pain through artistic or philosophical means. On its first section, it also examines the content of the biggest fragment of the play which refers to the experience of pain and that reveals the role of social constructions in human nature when it communicates itself. The second part of this essay is based on the ending of the play which proposes a metadiscursive thought about the possibility of staging pain, transferring the problem to philosophy. Finally, different ways of resolutions are proposed in order to arrive to a conclusion by proposing a conceptualization inside the limits of what is thinkable, which aspires to the construction of interpretations that transform and give meaning to experience.

Keywords: aesthetic experience, pain, human nature, biodrama.

Este artículo se lleva a cabo en el marco de la beca de doctorado otorgada por CONICET. 
En el año 2002 comenzó en el Teatro Sarmiento del Complejo Teatral Buenos Aires un ciclo denominado «Biodrama, biografías escenificadas» que continúa hasta la actualidad. Vivi Tellas, quien ideó el ciclo, lo propuso como una línea de investigación que indaga sobre la posibilidad de un "teatro documental». La propuesta consiste en convocar a un director y un dramaturgo para que desarrollen un proyecto teatral en torno a la vida de un(a) argentino(a) vivo(a). Estas premisas amplias produjeron obras muy diferentes, entre ellas elegimos una de Daniel Veronese, La forma que se despliega, que se estrenó en el año $2003 .^{2}$

Esta propuesta resultó peculiar, ya que no se ajustó totalmente a las reglas del ciclo y fue criticada por ello (Cruz, 2003: 4). La obra no se basó en la vida de una persona real, ni utilizó documentación para relatar la historia de un padre y una madre (sin nombre propio) que vivencian las secuelas de la muerte de su hijo. Sin embargo, aunque no es nuestro objetivo principal, esperamos mostrar a lo largo del trabajo que su inserción en la línea de investigación de un teatro documental es pertinente. No tanto porque lleve adelante este proyecto respetando sus consignas, sino más bien porque propone una reflexión meta-discursiva que indaga, con los recursos propios del arte teatral, la posibilidad misma de existencia de un biodrama. Específicamente, la obra se estructura en torno a interrogantes tendientes a esclarecer las condiciones de posibilidad para abordar de manera radical el dolor humano a través del arte teatral.

Consideramos que en este caso la reflexión teatral aporta a la filosofía, ya que sostenemos que, como afirma Paul Ricoeur, la representación se efectúa en un esquema triangulado en el cual la trama y el espectador se instancian en el horizonte del mundo. En la interacción entre estos tres elementos (trama, receptor y mundo) el texto se convierte en obra (1983:148) y por ello resulta que reflexionar sobre un hecho teatral no restringe el análisis al ámbito estético sino también, y sobre todo, vehiculiza una meditación filosófica sobre el mundo.

\section{EL DOLOR «TAL COMO ES VIVIDO»}

Al llegar al teatro el espectador sube al escenario, donde se sienta en gradas que delimitan un espacio sumamente íntimo. En el centro hay dos sillones y una mesa de living, donde están ya sentados los tres personajes: el «padre», la «madre» y el «pianista». La convivencia entre espectadores y actores es sumamente cercana. La luz es blanca, ilumina a todos por igual y no tiene variantes durante el espectáculo. La madre y el padre están sentados juntos. En otro sillón, a su izquierda, el pianista toca algunas notas en un piano de juguete.

Esta obra tuvo diferentes versiones hasta la actualidad y fue representada luego en otros teatros, con distintos elencos y variaciones en su texto, su puesta en escena y su cantidad de personajes. Se trabajará aquí con la primera versión, tanto del texto como de la puesta, que se puso en escena en el Teatro Sarmiento en el año 2003. Ficha técnica de la obra: La forma que se despliega de Daniel Veronese. Dramaturgia: Luis Cano. Dirección: Daniel Veronese. Intérpretes: Claudio Dapasano, Stella Galazzi, Guillermo Arengo. Iluminación: Gonzalo Córdova. 
Este personaje dice las primeras palabras, ${ }^{3}$ pero resulta complejo para el espectador detectar qué rol juega en esa situación: tilda de «niños» ${ }^{4}$ a la pareja, toca un piano de juguete y se mantiene en un incómodo silencio durante todo el resto de la representación, con mínimas intervenciones. Las conjeturas sobre la identidad del tercer personaje a lo largo de la obra son múltiples y varían de acuerdo al espectador: el fantasma del hijo muerto, un amigo antiguo que cayó incauto en esta pesadilla, un psicoanalista, etc. Finalmente la obra aclara que se trata de un artista intentando comprender o experimentar el dolor para luego recrearlo. El personaje es "pianista», sin embargo no es difícil situar allí al dramaturgo, y por nuestra parte, también al filósofo. Por otro lado, el espectador puede identificarse con este «oyente» que asiste, así como él, de forma silenciosa, al dolor incesante de la pareja.

El matrimonio comienza hablando de sus propios padres, del momento en que se conocieron, del amor frustrado que resultó la pareja que conformaron y sobre todo de una idea que los unió desde el principio: el deseo de tener un hijo. El relato conduce al hijo, el hijo a sus fotos y paulatinamente nos damos cuenta de que el hijo ha muerto. De forma evidente ambos hacen esfuerzos por evitar el tema. Centran su energía en reproches mutuos con respecto a su relación de pareja. El tema del hijo vuelve de forma implacable. Cuando el pianista canta «los niños no tienen hijos» (Veronese, 2003: 7) dejan de lado la resistencia para comenzar a hablar de la pérdida, la única verdad que parecen poder decir.

En éste el conflicto de la pareja comienza a diluirse para hacer pasar a primer plano la reflexión sobre la vivencia misma del dolor. En algunos momentos los personajes parecen relatar genuinamente su estado de ánimo, ${ }^{5}$ en otros recurren a lugares comunes, ${ }^{6}$ aspirando quizá a que esas palabras gastadas adquieran un significado genuino. La obra termina con la revelación de lo que ya sabemos, pero que sin embargo se nos presenta como una verdad sorprendente: este padre y esta madre son sólo actores, este músico que los observa también lo es, y estamos asistiendo a la representación de un dolor que es del mundo y que quizá no sea de ningún modo representable.

La obra y los personajes ayudan a recrear fenomenológicamente el dolor «tal como es vivido", aunque la madre dice que no podemos ponernos «bajo la piel» (2003: 10) de una madre que sufre, que su dolor está «enquistado» en ella. Afirma, el dolor está anclado en

«Pianista: Niño. Niña (A público) Estos niños que ahora están de moda, creen que este piano es fácil de tocar. Fácil. Como mentir. (Sonríe. A ellos) Niños. (Pausa. A público) En realidad estos niños están aquí para tocarme a mí. Quieren oír mi nota más grave. Y creen que yo también soy fácil de tocar. Como este piano. Pero a mí nadie puede hacerme hablar. (Pausa) En un momento voy a decir basta. No me hagan caso cuando diga basta» (Veronese, 2003: 1).

4 Que el pianista denomine «niños» a los padres durante toda la pieza, da lugar a múltiples lecturas que no podremos abordar aquí. En nuestro caso podemos circunscribir la referencia a dos series de observaciones que se realizarán más adelante en el texto: la primera cuando al analizar el paradigma de naturaleza humana vigente observamos que la experiencia del dolor no encuentra contexto en él (y por ello estos padres no se comportarían como adultos, sino más bien como niños, o animales), la segunda cuando se piensa la relación que el arte y el pensamiento pueden llegar a establecer con el sufriente, reduciéndolo a un objeto de estudio que no tiene posibilidad de reflexionar teóricamente sobre su propia experiencia.

5 «Madre: Veo a los demás y me quiero morir, veo a una persona feliz y me quiero morir. No entendés que odio la vida que llevo pero que no solucionamos nada con un vestido limpio» (Veronese, 2003: 9).

6 «Antes pensaba: son cosas que siempre les pasan a los demás, nunca a nosotros mismos [...] Antes yo decía: El mundo es un escenario —así lo siento yo—»(Veronese, 2003: 10). «Estamos heridos de muerte. Somos sobrevivientes de un naufragio» (Veronese, 2003: 13). 
el cuerpo. Tal como la fenomenología nos propone, el cuerpo aquí no es pura materia, confundido en el mundo de las cosas, sino que es "cuerpo vivido", un cuerpo sufriente. Usando la distinción husserliana, podemos decir que no estamos ante un fenómeno del Körper, sino del Leib. La vivencia del dolor ancla la subjetividad en el cuerpo y funda un mundo de experiencias y significados nuevos. Según Merleau-Ponty el cuerpo propio es el que nos pone en relación primordial con el mundo y en este sentido el dolor por la muerte del hijo proyecta, para estos padres, un mundo distinto al que antes habitaban. Ante la nueva experiencia todo se resignifica.

El anclaje en el cuerpo se evidencia además en la vivencia del espectador. Durante la obra el dolor se transmite en un plano diferente al del lenguaje. La personificación de los actores, sus cuerpos sintiendo dolor en ese momento, son los que se comunican con el público. Según Merleau-Ponty la afectividad es un tipo de intencionalidad que consiste en no ser una relación entre conciencia y objeto sino una "tendencia de un cuerpo hacia otro cuerpo realizada en el plano del mundo» (1994: 173). Esta tendencia se verifica para el espectador, ayudado por la cercanía e intimidad de su convivencia con los actores.

En algunos momentos la comunicación corporal se hace más patente por su marcado contraste con las palabras. Por ejemplo, cuando la madre reprocha a su marido y a sí misma no haberle sacado fotos al hijo durante sus últimos meses. ${ }^{7}$ Para el espectador es fundamental el modo de transmisión de las palabras, la carga afectiva con que son dichas. En ese punto se comparte el dolor con los actores como algo que se transmite de cuerpo a cuerpo, con el sonido y la cadencia material de la voz, dejando a un lado el contenido del discurso.

Paradójicamente, mientras esta comunicación está ocurriendo los personajes sostienen una y otra vez que el dolor es una experiencia intransferible, en expresiones que resultan verosímiles al espectador. Una convicción, una fantasía o una creencia pueden ser comunicadas a otros con un grado de exactitud mayor, el dolor en cambio se presenta como algo inexpresable. Lo que se enuncia refiere sólo algo accesorio del dolor, sus causas o su forma, pero nunca la calidad de estar «enquistado» en el cuerpo propio. La transmisión que parece eficaz en el plano mudo de los cuerpos, se convierte en un imposible cuando se produce un intercambio en el lenguaje. La propiedad que tiene cada uno sobre su carne impide vivenciar lo que al otro le ocurre. La madre afirma:

Una lee en el diario que matan a un niño o lo secuestran y piden rescate. Es solo un ejemplo.
Inmediatamente se nos vuelve irreal. Se vuelve irreal y punto. O en las guerras, mujeres con
sus niños muertos en los brazos. Pensemos en esa situación concreta. Estamos cansados
de ver esas imágenes. ¿Pero podemos imaginar realmente lo que se siente en esa situación?
¿Alguien se puso verdaderamente debajo de la piel de esa madre? ¿Quién dice que sí? Quien
dice que sí, miente (Veronese, 2003: 10).

El dolor es vivido por los personajes como una experiencia que los aleja, una barrera entre ellos y los demás. Es sobre todo la actitud hipócrita de los otros frente al dolor lo que les molesta, lo que los hace sentirse distintos. Ante este reclamo reiterado, sería inte-

«Madre: No tenemos fotos, entienda bien, de los últimos años de nuestro hijo. No hay fotos. [...] Ahí tenés la cámara, a él. Él la miró y no dijo nada. Entonces la pongo arriba del mueble. Meses ahí, inmóvil. [...] le hubieses pedido al de la óptica que te enseñe, no importa, o haber aprendido sola a usarla, y deberías haberle sacado fotos a tu hijo en vez de esperar que alguien lo haga por vos» (Veronese, 2003: 7). 
resante preguntar cuál es el contenido, para estos padres, de la hipocresía de los demás. La madre dice:

¿Qué carajo me significaba eso de mirar esas imágenes y tener que sufrir yo también de verdad? O tener que sostener, por lo menos, una opinión racional, una mirada bien intencionada sobre la fatalidad. Hablar como si realmente se pudiera razonar, comprender el tema, para demostrarnos y demostrarles a todos, porque eso también se pide, que sufrimos con los que sufren. No sabemos de dónde viene, si es un mandato divino o qué, pero se nos arroja a esta vida, la que decimos que nos hace humanos, la que nos diferencia del animal, como teniendo la obligación moral de saberlo todo. ¿Y del dolor qué sabíamos? Nada. No sabíamos nada (2003: 11).

La hipocresía denunciada se manifiesta cuando los otros intentan comprender, dar opiniones, compadecerse (una frase usual ante la muerte: «lo acompaño en el sentimiento»). Estas racionalizaciones se presentan como supuestas comprensiones totales y no reconocen la dimensión inasequible, tan propia como el cuerpo, del dolor que los padres sienten. El fundar un discurso racional acerca del dolor permite borrar su ser más puro, su calidad no cuantificable, su singularidad. La supuesta comprensión por parte de los otros obtura, paradójicamente, la capacidad de los padres de dolerse con otros.

La diferencia más fuerte que notan entre ellos, dolientes, y otros que pretenden acompañarlos, es que esta compañía tiene aparejada una convicción oculta: "no me va a pasar a mí». ${ }^{8}$ Conocen esta actitud porque fue la que ellos mismos tuvieron - y siguen teniendo- frente al dolor ajeno. Ante esta situación de soledad los padres adoptan posiciones ambivalentes. El padre deduce de ello una lección moral bastante gastada: la moraleja es que ahora que sufren realmente aprendieron la lección; tendrían que haber ayudado a los otros cuando sufrían. Afirma:

Pero, escuche bien esto: ahora no es ajeno para nosotros. No. Y ahora creemos sin ninguna duda, sin ninguna duda, que tendríamos que haber sido más honestos y comprensivos con lo que antes veíamos. Comprometerse realmente con el dolor de los demás (2003: 12).

Los espectadores no sabemos si realmente el padre está poniendo en práctica este compromiso total con los demás. De todos modos, la madre propone una actitud diferente. Observa que ella misma huiría de sí misma si pudiera, que en los pocos momentos que puede hacer la experiencia de observarse como si fuera otra, el único deseo que tiene es escaparse. ${ }^{9}$ Casi ruega al pianista que no se compadezca de ellos, que no intente ser considerado. Esta actitud paradójica es, a nuestro juicio, más reflexiva que la del padre. En efecto, la lección moral que el padre infiere es bastante trillada y no se ha verificado la posibilidad de su cumplimento: hay que sufrir identificándose totalmente con el sufrien-

8 «Padre: Pero cuando le sucede a uno, desgraciadamente entonces son los demás los que dicen: «Ah, sí, claro, qué terrible lo que le pasa a ustedes. Pero sabemos que en el fondo lo viven como algo ajeno" (Veronese, 2003: 12).

9 «Madre: Yo en el fondo no culpo a los que ahora les toca esconder la cabeza. Claro que no. [...] Yo también me iría si pudiera. En realidad ahora a veces siento que me separo la piel del cuerpo, que puedo ponerme fuera de mí, entonces veo lo que ustedes ven ahora, me veo a mí misma como antes veía yo aquellas imágenes terribles del sufrimiento ajeno, pero la imagen me castiga sin piedad, porque me veo actuar el dolor puro como en un teatro, pero también tengo conciencia de mi realidad al mismo tiempo, la conciencia del dolor real, vivo, enquistado en ese cuerpo que puedo ver afuera pero que es el mío, no de otro, el mío y veo todo, lo veo todo y no hay salvación posible» (Veronese, 2003: 12). 
te. Contrariamente, la vocación y afirmación de la posibilidad total de empatía con el doliente parece concluir finalmente en la actitud hipócrita que los padres denuncian. La madre, antes que la hipocresía prefiere la soledad. Naturaliza la actitud de huida, observa que este impulso es el que tendría cualquiera ${ }^{10}$ y por ello valora más la sinceridad del que huye que la hipocresía del que se queda.

La aporía en esta situación es que de las dos formas (acompañados por farsantes que pretenden comprender todo o rechazados por hombres sinceros) los padres se quedan sufriendo en soledad. ¿Es esto una consecuencia intrínseca a este tipo de situaciones límite o podría haber otro posible punto de vista?, ¿por qué no puede replicarse o amplificarse en el plano de la comunicación lingüística lo que ocurre en el nivel de los cuerpos?, ¿es natural, como la madre pretende, la actitud de huida?, ¿es el dolor individual y singular, como los padres suponen? El problema que se nos plantea es, en definitiva, no el del dolor abstracto sino el del doliente inserto en un mundo humano. La pregunta se transforma en la indagación de las concepciones sociales del dolor que conducen a los padres a vivirlo como una soledad sin salida.

El dolor se hace más hondo cuando distingue y separa del resto del mundo, es menos vivible para el doliente en estas condiciones. Sobre todo si observamos que quien siente un dolor tan profundo es para los otros, a partir de ese momento, la personificación misma del dolor. De alguna forma, esta adscripción cosifica a los dolientes, les niega el estatuto humano.

Podríamos hablar entonces de una construcción social del dolor que está relacionada con una concepción esencializada y normativa de la naturaleza humana. En efecto, nuestras sociedades están construidas, como observa Susan Wendell (1996: 38), sobre el modelo de un «varón adulto, joven y no discapacitado» y podríamos agregar a ello: feliz. El estar dolido no parece formar parte de la condición humana «normal». En las sociedades de consumo la juventud del ideal humano es particularmente relevante. Este rasgo se vuelve pernicioso cuando los individuos se enfrentan a situaciones como la muerte de un hijo, a la enfermedad, a la decadencia, experiencias asociadas a las personas adultas. El ideal adolescente no brinda ningún tipo de modelización para ensayar salidas a ellas, ya que estas experiencias no se encuentran en la perspectiva de lo humano. ¿Cómo se enfrenta esta encrucijada? La salida nostálgica no parece la más adecuada: si hubo un modelo anterior de naturaleza humana adulta, fue asociado al manejo racional de las pasiones y tampoco había en él espacio para el dolor como un estado genuino.

En este sentido, en el modelo adolescente los sentimientos y las pasiones no están negados. Al contrario, el arquetipo del adolescente es puro sentimiento y poca razón. Se siguen explotando las viejas creencias de Occidente, aunque ahora invertidas (y esto se observa de forma potenciada en la publicidad): los sentimientos y las pasiones siguen siendo salvajes, rápidos, pasajeros, inmanejables, explosivos. Las pasiones se ven reflejadas en relaciones fugaces, en estallidos que van del llanto a la risa en pocos segundos. Se construye de una forma simplista un arquetipo opuesto al que primaba antes: lo que antes era reprimido es ahora exaltado, lo que era sucio y bajo aquí es la expresión más alta de la subjetividad. Se requiere ser "espontáneo», «impulsivo», «creativo», tener capacidad para cambiar de estado rápidamente.

10 «Madre: Uno necesita darse cuenta de que es al otro al que le sucede y no a uno» (Veronese, 2003: 11). 
Es por ello que ante experiencias como la muerte de un hijo, ninguno de los dos arquetipos funciona: el dolor no se puede refrenar por medio de la razón y resulta imposible transitar veloz desde el profundo pesar a la alegría histérica. El estado de tristeza es en este caso permanente en el sujeto, se hace normalidad y por tanto es difícil insertarlo en algún modelo social posible. Cualquier estado persistente (enfermedad, dolor, locura) es observado como aterrador. Para un mundo en el que rige la ilusión de la movilidad social permanente, del cambio continuo, el estado de quietud del doliente es insoportable.

La negación de la tristeza, del dolor, de la enfermedad produce vivencias disociadas, en las que estos fenómenos son relegados al ámbito privado, estrictamente individual y personal. Wendell lo explica diciendo:

Cuando las esferas pública y privada están divididas, las mujeres (y los niños) han sido frecuéntenme relegados a la vida privada, así como también lo han sido los discapacitados, los enfermos y la gente mayor. La esfera pública es la esfera de la fuerza, el cuerpo positivo (valorado), el desempeño y la producción, los no-discapacitados y los adultos jóvenes. La debilidad, la enfermedad, el descanso y la convalecencia, el dolor, la muerte y el cuerpo negativo (devaluado) son privados, generalmente se esconden y con frecuencia se descuidan (1996: 39).

En la obra, el padre reprende a la madre por hablar del dolor frente a extraños. Propone como escape salir, pasear, vestirse y arreglarse. La madre se niega: «para eso quedarse solo. Es lo mejor» (Veronese, 2003: 11). No hay posibilidad de hacer público el dolor. En la recepción de la obra sucede algo parecido: mientras el dolor es expresado indirectamente es soportable, pero luego, cuando se tiene frente de sí a esta mujer ya desbordada, que hace públicos y notorios sus sentimientos, el espectador se espanta de su dolor, siente ganas de escapar, de alejarse. Según Wendell:

Al salir al mundo público con una enfermedad, con dolor, o con un cuerpo devaluado, las personas encuentran resistencia a la mezcla de ambas esferas; la división se revela vívidamente. Gran parte de la experiencia de la discapacidad y de la enfermedad se oculta, porque no hay ninguna manera socialmente aceptable de expresarla y de que la experiencia física y psicológica sea reconocida (1996: 39).

Parecen existir dos opciones entonces: superar el dolor y reintegrarse al mundo, o definirse como dolientes y quedarse solos. Y es lógico que se suponga que el dolor debe ser superado si no es un estado esencial de la naturaleza humana. Los únicos estados persistentes pueden ser la alegría, la salud, la racionalidad. De algún modo se considera que los estados contrarios (tristeza, enfermedad, sinrazón) deben, por definición, ser estados transitorios. El dominio del dolor puede hacerse racionalmente (acatando un modelo que nos fue legado por la modernidad) o puede lograrse mediante actos heroicos extraordinarios desplegados por el individuo (acatando un modelo que nos fue legado por el cristianismo). Quedarse en el dolor, paradójicamente, es visto como un símbolo de debilidad y no de fortaleza.

A pesar de que, como Sontag afirma, la mayoría ha tenido alguna vez experiencias dolorosas, es casi inevitable concebir estas situaciones como únicas, individuales y excepcionales. Advierte que en estos casos las valoraciones sociales cambian y las obligaciones de quienes padecen son otras. Observa con respecto al cáncer: 
Al contrario de las despectivas observaciones de lo frágiles que son los amores y las lealtades sometidos al pánico de una epidemia, las crónicas sobre las enfermedades modernas —en que el reo no es la sociedad sino el individuo- parecen ignorar por completo lo mal que suele tomar un enfermo la noticia de que se está muriendo. Siempre la enfermedad mortal fue considerada como una ocasión para poner a prueba la entereza moral del moribundo (1996a: 46).

Y más adelante: «La enfermedad como una ocasión para ser bueno. Como mínimo, la calamidad del mal abre el camino para que discernamos en qué nos hemos engañado toda la vida y cuáles han sido nuestras fallas de carácter» (1996a: 47).

Los padres, y sobre ellos pesa esta mirada, deberían mostrar de alguna forma las nuevas utilizaciones que pueden hacer de este conocimiento del dolor. Ahora, dice el padre, saben sin ninguna duda todo lo mal que se portaron en el pasado. Aprendieron algo gracias al dolor y va siendo hora de superarlo "poniéndose un vestido limpio». Este enfoque para el que el dolor es algo privado, un estado pasajero a ser superado, conduce inevitablemente a atribuir al doliente la culpa por el dolor que continúa sintiendo. La madre asevera:

¿Sabe quién soy yo? Yo soy una mujer que hoy solo tiene una ambición: la de no encontrarse culpable. No quiero sentir culpa. Ya sé que no hice nada, pero ya le dije: soy muy insegura, en este momento es inevitable para mí no pensar que alguna vez en la vida hice algo malo, si no, no entiendo por qué me toca sufrir en este mundo (Veronese, 2003: 10).

La asignación de culpa ha variado, ya no se estila acusar a quienes sufren a través de la suposición de que son pecadores, pero sí se tiene "predilección por las explicaciones psicológicas» (Sontag, 1996a: 59). Es así como al interpretar la obra es casi inevitable realizar una mirada "psicologizante» (y de hecho varios comentarios sobre la misma se entregaron gustosos a esa vía de interpretación). Los primeros momentos, en los que observamos la profunda infelicidad de la pareja, aún cuando su hijo estaba vivo, pueden conducirnos a explicar el actual dolor como mera continuación del pasado.

Caemos en una trampa, diciéndonos que no nos ocurrirá a nosotros si sabemos construir una pareja, una familia. No es la muerte del hijo la que llena de dolor a los personajes, sino la incapacidad para amarse verdaderamente. Otra explicación en esta línea consiste en ver en la actitud de la madre un exceso: está dolida porque depositó en ese hijo demasiado deseo, porque dio sentido a su vida por la vida de ese otro. La enseñanza es que no debería haberse atado así, por el contrario debería haber construido una vida propia y seguir, por ejemplo, su vocación de tocar el piano. Para esta mirada la madre es una frustrada y le duele su frustración.

Estas lecturas serían consoladoras porque nos depositarían del otro lado del dolor, sin embargo, no resultarían del todo acertadas. Aun si esta pareja hubiera sido una unión ideal, aun si ambos fueran exitosos en sus profesiones, ¿no se hallarían dolidos por la muerte del hijo?, ¿no habrían perdido quizá en gran parte sentido sus vidas? Tener un refugio frente al dolor no borra la especificidad del dolor mismo. Una vía de escape (un amor, un trabajo) resulta efectiva, quizá, para cumplir con las expectativas sociales sobre cómo se debe afrontar el dolor. Nunca descarnadamente, nunca de modo visceral: el dolor se debe «tramitar» (con una metáfora psicoanalítico-burocrática), no «aullar»o «escupir» como hace el personaje de la madre. 
Afirma Sontag (1996a: 51) que en esta mirada la culpa es tan cruel como en la perspectiva cristiana: inconscientemente labraron su dolor, construyeron su vida tapando los sentidos profundos y hoy, después de haber hecho todo mal, sólo les queda sufrir. Y no sólo eso: hoy, ante semejante terreno devastado, tienen la oportunidad de redimirse y transformar por completo sus vidas.

De todas maneras, debemos ser muy cautos. En Sontag se puede observar algo así como un intento de describir «lo real en sí», la enfermedad despojada de todo significado. ${ }^{11}$ Este intento es infructuoso en sus límites y esperamos evitar, mientras denunciamos construcciones vigentes, crear otras nuevas que intenten relevarlas en la comprensión total de los fenómenos. Nuestro inicio fenomenológico muestra bien cuál puede resultar el desliz: si en el campo de los cuerpos el dolor es en principio comunicable, podríamos llegar a pensar que no hay nada propio, nada único, nada inexplicable en la experiencia del dolor. El teatro también nos ayudará a escaparnos de esta ilusión.

\section{LA IMPOSIBILIDAD DEL DOLOR}

El arte, en tanto su discurso no se dirime completamente frente a las categorías de «verdad» y «falsedad», es quizá un ámbito privilegiado en el planteo de lo complejo que resulta intentar dilucidar ciertas tramas de la experiencia. Como afirmamos al inicio, $\mathrm{La}$ forma que se despliega plantea el problema de la recreación de la experiencia del dolor a través del teatro, sin tomar ninguna como experiencia de dolor «real» o «verdadero». Es interesante volver a Aristóteles para pensar en este caso, ya que el filósofo afirmaba:

Lo más importante de estos elementos [de la tragedia] es la disposición de los hechos en sistema; pues la tragedia es representación [mímesis] no de hombres sino de acción, de vida [bion] y de felicidad (la desgracia reside también en la acción) y el objetivo buscado [telos] es una acción [praxias tis], no una cualidad [ou poiótes]; ahora bien, los hombres tienen tal o cual cualidad en función de su carácter, pero es en función de sus acciones como son felices o infortunados (Aristóteles, VI, 1450a).

Lo imitado no es nunca un hombre y su carácter, sino sobre todo la acción humana, la vida más allá de cómo es vivida por cada individuo particular. Siguiendo a Aristóteles, la falta de referentes reales de sufrimiento posibilita que la vida dé lugar a la representación ya que facilita la universalización de la experiencia del dolor y nos sumerge en la ilusión de tener la experiencia misma ante nuestros ojos.

También esta ilusión propia de la tragedia clásica se rompe bruscamente hacia el final de la pieza. Allí se revela la construcción meta-discursiva para cuestionar justamente la posibilidad de realizar un traslado de la vida al escenario. Ya en el transcurso de la obra se le había reprochado al personaje del pianista su observación interesada en contar, por medio de la música, el dolor de los padres. La madre lo increpa:

11 «No dar significado, propósito tradicional de todo esfuerzo literario, sino privar de significado: aplicar esta vez esa estrategia quijotesca, altamente polémica, ‘contra la interpretación` al mundo real. Al cuerpo. Mi finalidad era, sobre todo práctica» (Sontag, 1988: 100). 
A ver si lo llego a entender, ¿usted sería el encargado de poner un manto de belleza aquí, entre tanto dolor? ¿Cuando toca expresa algo que merece ser escuchado y cuando nosotros hablamos no? ¿Usted siente distinto que nosotros? Usted, claro, la belleza, lo sublime, el misterio de la creación (Veronese, 2003: 10).

\section{Y luego:}

No, porque este señor convierte el sufrimiento humano en belleza y habría que estar agradecido, parece. ¿Por qué? ¿Alguien se lo pide? No me gusta eso. En mí también hay belleza, el dolor verdadero me embellece. No hace falta que me muestre de una manera que no soy, que muestre su punto de vista sobre mí y el asunto. Eso también es esconder la cabeza (2003: 11).

El arte es para la madre un intento perverso de embellecer el dolor, a la vez que una manera aparentemente más sofisticada de alejarse de él. Las formas artísticas (también filosóficas) de la sublimación construyen una mirada que pretende ser universal y neutral frente al padecer humano. En el proceso los discursos se distancian de los modelos reales, los miran actuar sin darles respuesta, los instrumentalizan para dar lugar a sus propias pretensiones de trascendencia, generando una relación de conocimiento que no va de persona a persona sino de estudioso a objeto de estudio. El arte, con su vocación de expresar lo que por definición no puede ser expresado, cae en el más hipócrita de los abusos. La madre sostiene que es ella el reducto de la verdad descarnada, la representación sólo una copia degradada.

Sin embargo, no es ese el último paso — como en el platonismo, se abisma la degradación de lo real一. La obra nos pone brutalmente frente a una nueva verdad, que sabíamos pero negábamos sumergidos en la representación: nosotros somos espectadores, observando a unos padres ficticios que no son más que actores. No sienten tampoco ellos el verdadero dolor. El pianista dice:

Es terrible que estos niños mientan y actúen de esta manera el dolor ajeno. Lloran con tanta verdad por el hijo y yo no puedo. ¿Pero qué les importa a ellos el hijo? ¿Les importa un hijo a ellos? Si tuviesen los motivos que yo tengo seguramente se volverían locos, confundirían todo. (Pausa) Estos niños mintieron bien. (Toca y canta) Son actores (Veronese, 2003: 13).

Nosotros, espectadores, nos vemos enfrentados a nuestra condición de último eslabón, en una cadena cuya realidad ni siquiera está frente a nosotros, hallándose en algún otro lugar, fuera del teatro, en las vidas verdaderas que pasaron por esa experiencia. Los espectadores se mostraron incapaces de sentir el dolor que los personajes vivencian, pero finalmente los actores que los interpretan se muestran también imposibilitados de encarnar sus personajes. Un simulacro, frente a otro simulacro de algo que se revela lejano y confuso. El dolor queda intacto, en algún lugar que no podemos delimitar y nuestra experiencia fue la vivencia de una imposibilidad, de un límite. La obra cuestiona su mismo sentido y termina en un final vacío, que queda abierto en la interrogación a lo desconocido. ${ }^{12}$

12 «Pianista: Pero a mí nadie me llama mentiroso, Nadie me parte la cara. Nadie. Así estoy yo. Yo estoy sin poder decir ni hacer nada, por un hijo, por su vida. Soy un cobarde. Ya estoy afuera. Estoy solo. Esto no 
Frente a este mismo límite la filosofía podría adoptar diferentes actitudes. Una estrategia posible sería alejarnos y volver a los fundamentos del conocer para proponernos sondear - como lo hicieron Kant y otros- los límites de la razón y una vez demarcados circunscribir a ellos el campo de lo pensable con sentido. La filosofía se definiría como una mirada a la que incumbe sólo lo que puede conocerse, los hechos que pueden ser apresados mediante el lenguaje. Así, ante el dolor de los otros el discurso filosófico haría bien en alejarse si encuentra que lo único vivible es una empatía corporal sin palabras. Sin embargo, en la misma obra de Kant la empresa se lleva a cabo y se trasciende luego para desbordarse en el pensamiento de lo que se había postulado como impensable. La filosofía siempre parece dispuesta a rebasar los límites autoimpuestos.

En ese ímpetu devorador de lo real, el pensamiento filosófico ha llegado a fantasear con abarcar todo. Respecto del dolor, por ejemplo, Buber plantea que sumergiéndonos en nosotros mismos lograremos una "visión antropológica» que podrá dar cuenta de la «naturaleza humana» completa (1974: 19-23). Este planteo presupone que no hay diferencia radical entre los hombres, que cada uno puede encontrar en sí mismo todo aquello que puede ser propio de lo humano. Se borra desde esta perspectiva la especificidad del dolor sentido como propio para convertirlo en un trascendental de la experiencia. Sin embargo, como ya señalamos, es probable que este tipo de posturas desemboque en la actitud hipócrita que denunciaba la madre de la obra. Es decir, aunque es valorable que esta conceptualización de lo humano incluya al dolor dentro de la naturaleza humana trascendental comprendiéndolo como una experiencia constitutiva y no como una vivencia secundaria y necesariamente pasajera, su pretendida universalidad y accesibilidad inmediata borra en la práctica la especificidad, la diferencia de quien ahora sufre con quien sólo se sumerge en sí mismo para comprender el dolor. ${ }^{13}$ Podemos suponer que el anclaje corporal del dolor impide una generalización tal. Cada cuerpo se constituye como una perspectiva particular y, en tanto lo es, su experiencia no sólo resulta única, sino también otra que la de todo aquello que es diferente a él. Así, aun en el plano básico de los cuerpos que se comunican, habrá que tener en cuenta la diferencia. Podríamos retomar, para cerrar esta crítica, una sugerencia de Wendell ${ }^{14}$ cuando plantea que las posturas postmodernas, para las que el cuerpo es un tipo de representación cultural, terminan por negar su sufrimiento y padecimientos sentidos. Estas teorías funcionan como materia mistificadora en tanto olvidan la dimensión carnal de la experiencia.

Por último, esperamos que la filosofía pueda recorrer otro camino para tematizar lo aparentemente inabordable, que consista en acercarse a los límites del pensamiento para quedarse en ellos, realizando intentos múltiples y siempre infructuosos de apresar lo que no puede pensarse ni decirse. Este camino no rechaza lo indecible o impensable, sino que permanece en su terreno, aunque sin la ilusión de agotar los posibles significados de lo real. Precisamente, preguntarse o plantearse el problema del límite del pensar consiste en recorrer una y otra vez ese límite, logrando en el recorrido múltiples transformaciones.

es nada, no es música, no tiene ni principio ni final. Y sin embargo... Fin» (Veronese, 2003: 11).

13 Nietzsche elabora un argumento interesante al respecto, afirmando que si esta comprensión o «compasión» frente al prójimo fuera posible, entonces deberíamos llegar a odiarlo cuando él se cree merecedor del odio (Aurora, L. I, af. 63).

14 «En la mayor parte de la teorización cultural posmoderna acerca del cuerpo no hay ningún reconocimiento de -y que yo sepa, no cabe reconocer- las arduas realidades físicas que enfrentan las personas con discapacidades» (Wendell, 1996: 51). 
Esta perspectiva supone un movimiento pendular de identificación y distancia, en el que el arte funciona como una forma de confrontación virtual con la vivencia, a la vez que propicia la creación del espacio meditativo necesario para pensar. Es forzoso vivenciar la empatía y a la vez apartarse de ella para reflexionar, tal como propone una representación escénica del dolor, que lo alcanza sólo porque puede efectivizar a la vez un movimiento de mimesis y conceptualización. ${ }^{15}$

Consideramos que evitar sentidos fáciles no nos despoja completamente de los sentidos atribuidos enfrentándonos con la verdad, como parece ser la ilusión de Susan Sontag en sus obras sobre la enfermedad. Aquí nos reconoceremos nuevamente deudores de Paul Ricoeur, recordando que no hay nada que no sea interpretación de relatos y reconfiguración de la interpretación de relatos, pero esto, lejos de disolver el sentido, reestructura la identidad creando nuevas significaciones. Plantear las paradojas de la naturaleza humana, tal como hemos intentado hacer con la experiencia del dolor, implica un ejercicio sin final, el mismo con el que termina la obra. Hacerlo, es decir, intentar pensar sobre lo que no es fácil de explicar es, al menos, un modo de evitar explicar fácilmente.

\section{REFERENCIAS}

Aristóteles. (1992). Poética. Madrid: Gredos.

Buber, Martin. (1974). ¿Qué es el hombre? México: Fondo de Cultura Económica.

Cruz, Alejandro. (2003). Daniel Veronese, con sus propios fantasmas. Diario La Nación

(Sección Espectáculos) del 21 de octubre de 2003, p. 4.

Horkheimer, Max. (1970). Observaciones sobre la antropología filosófica. Sobre el concepto del hombre y otros ensayos. Buenos Aires: Sur.

Merleau-Ponty, Maurice. (1994). Fenomenología de la percepción. Barcelona: Península.

Ricoeur, Paul. (1983). Tiempo y narración: La triple mímesis. Tiempo y Narración I. México: Siglo XXI.

-. (1984). La vida: un relato en busca de un narrador. Política y Educación. Buenos Aires: Docencia.

Sontag, Susan. (1996a). La enfermedad y sus metáforas. Madrid: Taurus.

- (1996b). El sida y sus metáforas. Madrid: Taurus.

-. (2003). Ante el dolor de los demás. Buenos Aires: Alfaguara.

Veronese, Daniel. (2003). La forma que se despliega. Archivo del Complejo Teatral de Buenos Aires.

Wendell, Susan. (1996). The Rejected Body. Feminist Philosophical Reflections on Disability. Nueva York: Routledge.

Recepción: enero de 2009

Aceptación: abril de 2009

15 Seguimos en estas afirmaciones algunas ideas que propone Sontag respecto a la fotografía sobre la guerra, en Ante el dolor de los demás (2003). 